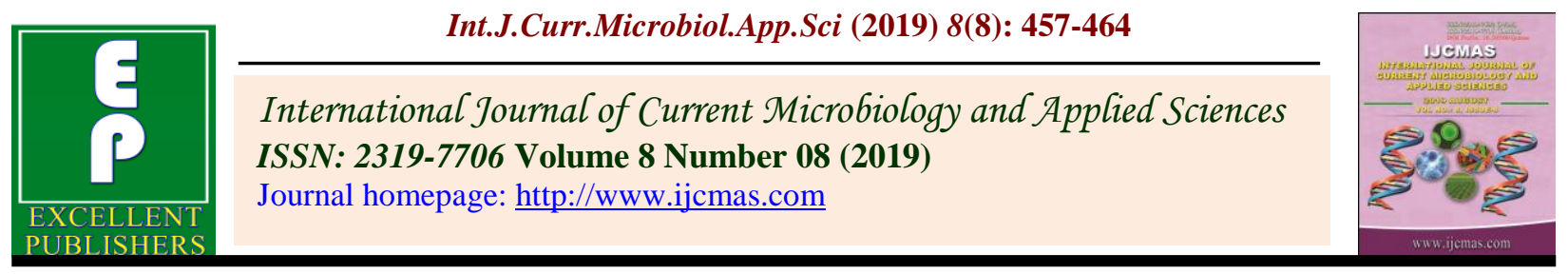

Original Research Article

https://doi.org/10.20546/ijcmas.2019.808.052

\title{
Expression of GATA4 Gene into Differentiated Canine Induced Pluripotent Stem Cell
}

\author{
Purnima Singh, Tanmay Mondal, N. Mahalakshmi, Kuldeep Kumar, \\ A.P. Madhusoodan, Mihir Sarkar and Sadhan Bag*
}

Division of Physiology and Climatology, Indian Veterinary Research Institute, Izatnagar, Bareilly (UP)-243122, India

*Corresponding author

\begin{tabular}{|l|}
\hline Key w or d s \\
Heart failure, \\
Myocardium, \\
Oxygen \\
\hline Article Info \\
\hline $\begin{array}{l}\text { Accepted: } \\
\text { 07 July 2019 } \\
\text { Available Online: } \\
\text { 10 August } 2019\end{array}$ \\
\hline
\end{tabular}

A B S T R A C T

Induced Pluripotent stem cells (iPSC) technology is involved in advancing the field of disease modelling and cell transplantation. Stem cell can differentiate under appropriate in vitro and in vivo conditions into different cell types. Under this study, we analysed the establishment of in vitro expression of GATA4 gene in cardiac differentiated canine iPSC. In vitro differentiation of canine iPSCs via embryoid bodies (EBs) was produced by 'Hanging Drop' method. EB's were differentiated by using cardiac differentiation media. During differentiation, EBs was collected on day 4, 6, 8, 12, 16, 20 and 24 for characterization of cardiomyocytes specific marker expression. Total RNA from EBs was extracted by using the Trizol method and subsequently, cDNA was synthesized. The differentiated cells expressed cardiac-specific gene GATA 4 which started from day 4 of differentiation. Relative expression of cardiac-specific genes revealed that ciPSC has the potential to differentiate into cardiomyocytes which can be used for cardiac tissue regeneration and as disease models for pharmaceutical testing.

\section{Introduction}

Heart failure is the leading cause of death in most developed countries and a growing cause of death in emerging countries. The most common reason of heart failure is myocardial infarction (MI), which is a damage of myocardium because of oxygen and nutrient deficit and replacement with non-contractile scar tissue. A primary challenge in developing therapies for cardiac muscle repair is the limited regenerative capacity of the myocardium (Laflamme et al., 2011). While recent research has established that the adult heart contains a sub-population of multipotent stem cells capable of heart regeneration only $1 \%$ at most of the cardiomyocytes is replaced annually and thus cannot repair the significant cardiac damage that occurs during MI. Currently, the only long-term treatment 
available to restore cardiac function after MIrelated heart failure is heart transplantation. Further, there are a large number of patients who do not qualify for heart transplant but could still benefit from heart repair. Cardiac tissue engineering and cell-based therapies, including direct cell injection, are potential approaches for treating cardiac disease. Cell injection is a straightforward method that directly injects cells into the target tissue to restore its function. Cardiac tissue engineering seeks to engineer myocardium in vitro and implant it at the site of injury to restore function to the infarcted heart muscle tissue Cardiomyocytes produced from iPSC are very similar in characteristics (morphology, marker expression, electrophysiological features, and sensitivity to chemicals) to the CMs of cardiac muscle and to $\mathrm{CMs}$ produced from differentiated ESCs. The pluripotent stem cells generation by iPSC technology offers a potential strategy to generate patient-specific pluripotent stem cells. iPSC are a type of pluripotent stem cell artificially derived from a non-pluripotent cell, typically an adult somatic cell, by inducing a "forced" expression of specific factors. These cells have the capacity to differentiate into all cell types (Hayashi et al., 2012; Yanagimachi et al., 2013) and, therefore, have significant potential for autologous stem cell therapies (Hanna et al., 2007; Alipio et al., 2010). This also provides a fascinating route to generate patient-specific pluripotent cells as disease models and drugtesting systems (Yu et al., 2007). The GATA factors GATA4 and GATA6 redundantly regulate the onset of cardiac differentiation (Zhao et al., 2008). In an experiment developing mice lacking GATA-4 die in utero because of myocardial defects, suggesting an absolute requirement of GATA-4 for heart development (Kuo et al., 1997; Molkentin et al., 1997). Grepin et al., 1997 examine the role of the zinc finger cardiac transcription factor GATA-4 in P19 EC cells. In the absence of cell aggregation, GATA-4 overexpression induced subtle cellular changes, including downregulation of embryonic markers Oct-4 and SSEA-1. With cell aggregation, GATA-4 overexpression led to an increased abundance of mRNAs for transcription factors (Nkx2.5, MLP, and Mhox), contractile proteins (cardiac troponin $\mathrm{C}$ and -MHC), and peptide hormones (brain natriuretic peptide) and accelerated the expression of terminal differentiation markers. Thus, GATA-4 contributes to the differentiation of mesodermal cells, activates the cardiac gene program, and may be a nuclear target for inductive and/or differentiation signals in committed cardiomyocyte precursors.

5-azacytidine (5-aza) is a cytosine analog, it is an effective DNA hypomethylating agent, and it is capable of altering the expressions of certain genes (Mohandas et al., 1981; Branch et al., 1996) regulating cell differentiation (Jones and Taylor, 1980; Bartoluccietal, 1989). Several studies have found that mesenchymal stem cells can be transformed into cardiomyocytes after an exposure to 5-aza (Makino et al., 1999; Hakuno et al., 2002; Rangappa et al., 2003). In addition, human ES cells (Xu et al., 2002) and stem cell antigen-1 (Sca-1) + cardiac progenitorcells (Oh et al., 2003) were differentiated into cardiomyocytesin response to 5-aza or 5-aza2'-deoxycytidinetreatment.Inthis study, weexposed reprogrammed canine induced pluripotent stem cells (ciPSCs) to invitro cardiomyocyte differentiation process using 5azacytidine and analysed the differentiated cells for expression of cardiac specific genes.

\section{Materials and Methods}

\section{Culture and cardiomyocytes differentiation from canine iPSCs}

The ciPSCs generated by pLentG-KOSM plasmid vector (Cell Biolabs, Cat no. LTV 
700) was used for this experiment, ciPSCs were cultured with Knock Out DMEM/F12 (GIBCO: 10829-018) supplemented with 20\% fetal calf serum, $1 \%$ non-essential amino acids, $2 \mathrm{mmol} / \mathrm{l} \mathrm{L}$-glutamine, and $100 \mu \mathrm{mol} / 1$ $\beta$-ME, LIF and BFGF. The differentiation ability of ciPSC were examined by hanging drop culture. Briefly, a single cell suspension of ciPSCs $\left(2.5 \times 10^{4}\right.$ cells $\left./ \mathrm{ml}\right)$ was prepared in differentiation media consisting of IMDM supplemented with FBS 10\%, NEAA(100X) $0.5 \%, 100 \mu \mathrm{MB}-M e r c a p t o e t h a n o l$ and $0.1 \mu \mathrm{M}$ azacytidine. From this cell suspension, $20 \mu \mathrm{l}$ was pipette on to the lid of a tissue culture dish and inverted over its bottom dish containing $5 \mathrm{ml}$ phosphate-buffered saline. On day 3, the embryo bodies (EBs) was transferred on gelatin coated cover slip in 6 well tissue culture dishes and grown up to day 24, with periodical changing of the media. During differentiation, EBs was collected on day $4,6,8,12,16,20$ and 24 for characterization of cardiomyocytes specific marker expression.

\section{Molecular characterization}

Total RNA was extracted and cDNA was prepared using a cDNA Synthesis kit (QuantiTect ${ }^{\circledR}$ Reverse Transcription Kit), from the collected samples. Reverse transcriptasepolymerase chain reaction (RT-PCR) and semi-quantitative gene expression analysis was carried out using Real-Time PCR system (Bio-Rad, USA) with SsoFast ${ }^{\mathrm{TM}}$ Eva Green supermix (Bio-Rad, USA) and the canine specific primers for GATA4: F-GGCC CTGAAGCTCTCCCCACAAG, R-AAGGC CAGGCTGTTCCAAGGGTC, annealing temperature of $63^{\circ} \mathrm{C}$. The endogenous house keeping control gene was considered as the glyceraldehyde 3-phosphate dehydrogenase GAPDH F-CCATCTTCCAGGAGCGAGAT, R-TTCTCCATGGTGGTGAAGAC annealing temperature $\left(\mathrm{C}^{\circ}\right)$ 55. Each PCR product was size-fractionized by $2 \%$ agarose gel electrophoresis and bands were visualized with a UV trans-illuminator (Bio Rad).

\section{Results and Discussion}

In the present study, ciPSCs (Fig. 1) were differentiated into cardiomyocyte by using azacytidine. It was observed that the EBs when treated with differentiation media, the morphology of cells changed and spreading of EBs was extensive at the periphery (Fig. 2). Cardiac specific marker expression studies by RT-PCR and gel electrophoresis revealed that GATA4 expression started from day 4 , and continued till day 24 of differentiation (Fig. $3)$. It was observed that the initially the expression was low but over the time of differentiation, the expression level was enhanced and higher expression was observed on day 24 of differentiation. However, no beating clusters were observed during the entire period of differentiation.

Several groups have reported that 5azacytidine, a demethylating agent, induced the differentiation of mesenchymal stem cells into cardiomyocytes in vitro (Makino et al., 1999; Hakuno et al., 2002; Fukuda, 2003). Treatment of human ESCs with $0.1 \mathrm{mM}$ of 5azacytidine for 1-3 days significantly increased the number of beating cells and simultaneously enhanced the expression of cardiac-specific markers (Yoon et al., 2006). 5'- azacytidine can cause extensive demethylation of 5-methylcytosine and reduce DNA methyl transferase activity in the cell (Haaf and Schmid, 2000). Study on murine iPSC differentiation by media containing betamercaptoethanol have shown the expression of marker genes for cardiac mesoderm, and cardiomyocytes including Mesp1, GATA2 (FOG-2), GATA4, Nkx2.5, Tbx5, Tbx20, atrial natriuretic factor (ANF), MLC2a, alpha$\mathrm{MHC}$, and cardiac troponin $\mathrm{T}$ in differentiation cultures of iPS cells. 


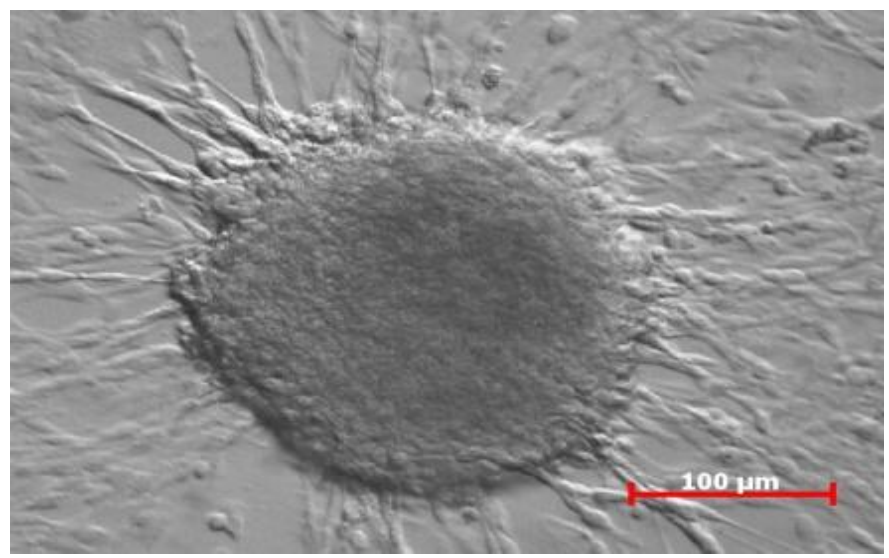

Fig. 1: Canine induced pluripotent stem cells derived from adipose tissue cultured on MEF feeder layer at passage 17. (4x magnification)

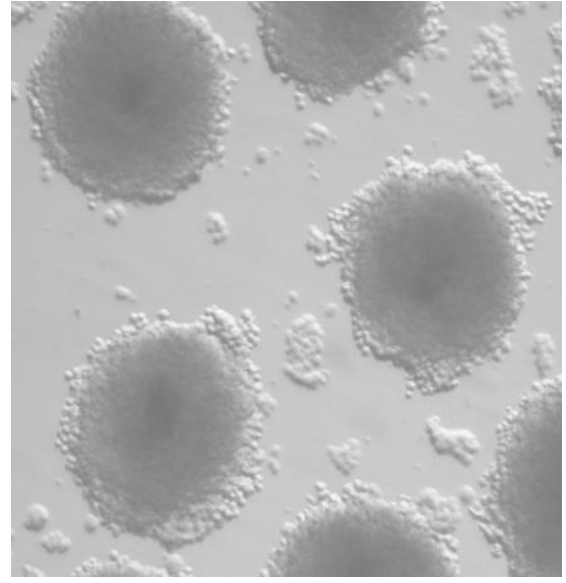

A

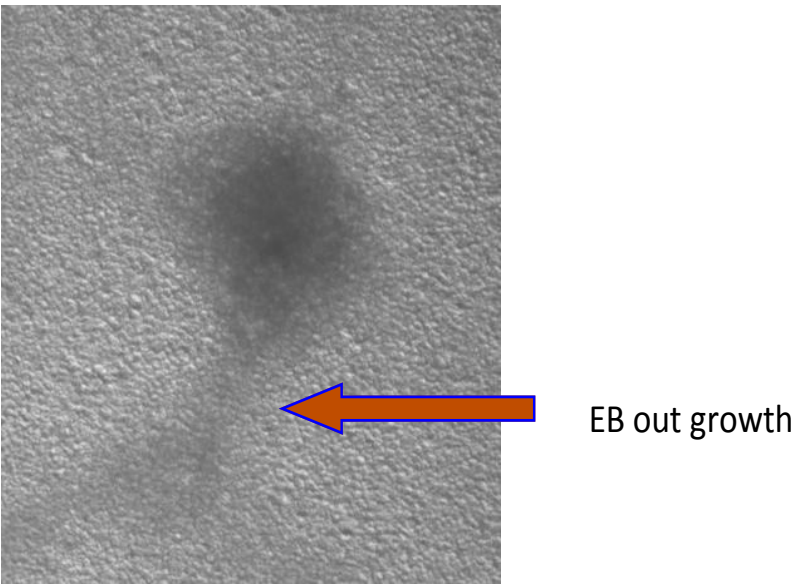

B

Fig. 2: A. In-vitro differentiation of iPSCs into Embryoid body (EB) formed after culture of iPSC in hanging drop method. B. differentiation of Embryoid body made from canine iPSC culture on MEF feeder layer. 


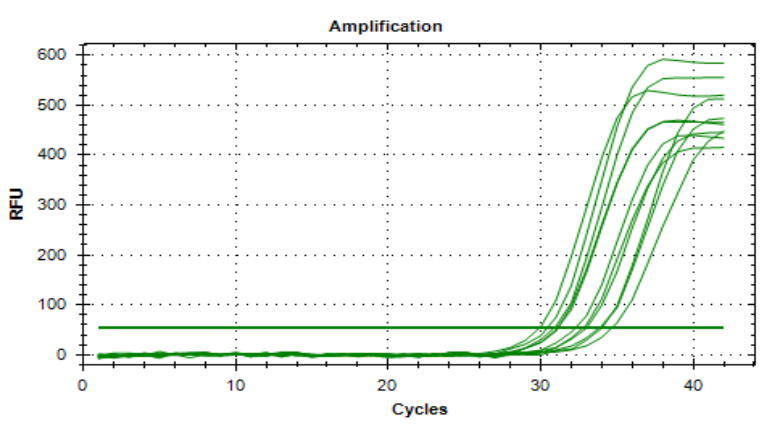

A

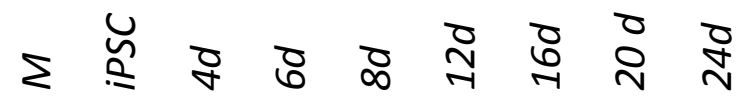

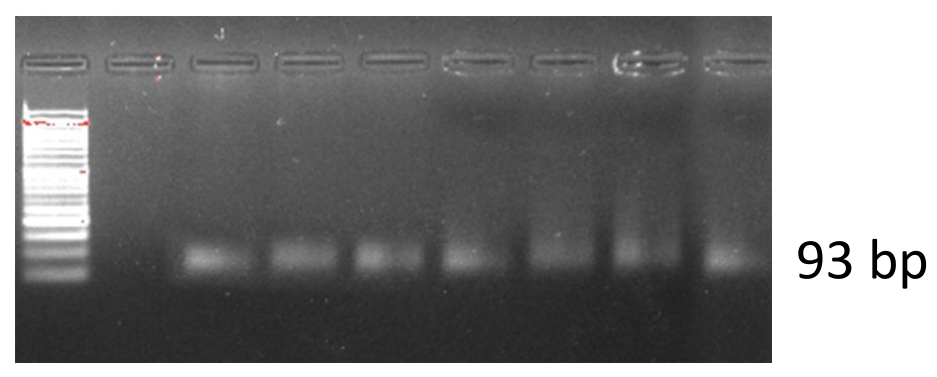

C

Fig. 3: Amplification curves and melting peaks of cardiac specific gene. A. Amplification curves of GATA 4. B. Melting curves of GATA 4. C. Molecular characterization of cardiac specific gene. Gel electrophoresis of PCR amplified product of cardiac specific gene in $2 \%$ agarose gel. Cardiac specific gene: GATA 4. Lane M: 50 bp ladder.

Immunocytology also confirmed the expression of cardiomyocyte-typical proteins including sarcomeric alpha-actinin, titin, cardiac troponin T, MLC2v (Mauritz et al., 2008). Several research groups have produced functional cardiomyocytes (CMs) in vitro from murine and human iPSCs (Medvedev 2010). Cardiomyocytes produced from iPSC are very similar in characteristics (morphology, marker expression, electrophysiological features, and sensitivity to chemicals) to the CMs of cardiac muscle and to $\mathrm{CMs}$ produced from differentiated ESCs. Moreover, murine iPSCs, when injected, can repair muscle and endothelial cardiac tissues damaged by cardiac infarction (Medvedev, 2010).

In case of canine iPSCs, Joseph Wu's group has demonstrated the preclinical potential of ciPSCs by treating immunodeficient mouse models of myocardial infarction and hind limb ischemia with transplanted endothelial cells derived from ciPSCs (Lee et al., 2011). 
As there is no standard protocol for differentiation of induced pluripotent of canine, the protocol was tested which have been used for cardiomyocytes generation from mouse/human ESC or iPSC. In the present study there was no beating clusters generated indicating that other methods may be tested for generation of beating cardiomyocytes from ciPSCs.

iPSCs have been revealed to be useful for study the phenotypes and disease mechanisms in cells of variable mutations and other genetic disorder. These properties of iPSCs are expected to make them a powerful tool for providing new therapeutic insights in the era of precision medicine. The results suggested that canine iPSCs were readily differentiated into cardiomyocytes as evidenced by the expression of cardiac specific marker. This finding demonstrates the potential for using canine induced pluripotent stem cells for cardiac tissue regeneration and as disease models for pharmaceutical testing. The iPSC technology will contribute to personalized, predictive, preemptive, and precision medicine (Mirnezami et al., 2012).

\section{References}

Ali, S. $\quad$ R., Hippenmeyer, S., Saadat, L. V., Luo, L., Weissman, I. L. and Ardehali, R. (2014). Existing cardiomyocytes generate cardiomyocytes at a low rate after birth in mice. Proc. Natl. Acad. Sci. 111: 8850-8855.

Alipio, Z., Liao, W., Roemer, E.J., Waner, M., Fink, L.M., Ward, D.C. and Ma, Y. (2010). Reversal of hyperglycemia in diabetic mouse models using inducedpluripotent stem (iPS)-derived pancreatic $\beta$-like cells. Proc. Natl. Acad. Sci. 107(30): 13426-13431.

Bergmann, O., Bhardwaj, R. D., Bernard, S., Zdunek, S., Barnabé-Heider, F., Walsh, S., Zupicich, J., Alkass, K., Buchholz,
B. A., Druid. (2009). Evidence for cardiomyocyte renewal in humans. Science. 324: 98-102.

Garbern, J. C. and Lee, R. T. (2013). Cardiac stem cell therapy and the promise of heart regeneration. Cell Stem Cell. 12: 689-698.

Hakuno, D., Fukuda, K., Makino, S., Konishi, F., Tomita, Y., Manabe, T., Suzuki, Y., Umezawa, A. and Ogawa, S. (2002). Bone marrow-derived regenerated cardiomyocytes (CMG cells) express functional adrenergic and muscarinic receptors. Circulation, 105(3): 380-386.

Hanna, J., Wernig, M., Markoulaki, S., Sun, C.W., Meissner, A., Cassady, J.P., Beard, C., Brambrink, T., Wu, L.C., Townes, T.M. and Jaenisch, R. (2007). Treatment of sickle cell anemia mouse model with iPS cells generated from autologous skin. Science. 318(5858): 1920-1923.

Hayashi, K., Ogushi, S., Kurimoto, K., Shimamoto, S., Ohta, H. and Saitou, M. (2012). Offspring from oocytes derived from in vitro primordial germ cell-like cells in mice. Science. 338(6109): 971975.

Hoffman, A.M. and Dow, S.W. (2016). Concise review: stem cell trials using companion animal disease models. Stem Cells. 34(7): pp. 1709-1729.

Jones, P.A. and Taylor, S.M. (1980). Cellular differentiation, cytidine analogs and DNA methylation. Cell. 20(1): 85-93.

Kajstura, J., Urbanek, K., Perl, S., Hosoda, T., Zheng, H., Ogórek, B., FerreiraMartins, J., Goichberg, P., RondonClavo, C., Sanada, F. and D'Amario, D. (2010). Cardiomyogenesis in the adult human heart. Circ. Res. 107: 305-315.

Laflamme MA, Murry CE. Heart regeneration. Nature. 2011; 473(7347): 326-35.

Lee, A.S., Xu, D., Plews, J.R., Nguyen, P.K., Nag, D., Lyons, J.K., Han, L., Hu, S., 
Lan, F., Liu, J. and Huang, M. (2011). Preclinical derivation and imaging of autologously transplanted canine induced pluripotent stem cells. Journal of Biological Chemistry. 286(37): 32697-32704.

Lompre AM, Nadal-Ginard B and Mahdavi V (1984). Expression of the cardiac ventricular alpha- and beta-myosin heavy chain is developmentally and hormonally regulated. J Biol Chem, 259: 6437-6446.

Lompre, A.M., Schwartz, K., d'Albis, A., Lacombe, G., Van Thiem, N. and Swynghedauw, B. (1979). Myosin isoenzyme redistribution in chronic heart overload. Nature. 282(5734): p. 105.

Lyons, G.E., Schiaffino, S., Sassoon, D., Barton, P. and Buckingham, M. (1990). Developmental regulation of myosin gene expression in mouse cardiac muscle. The Journal of cell biology. 111(6): 2427-2436.

Ma, L. (2011). Murry CE. Heart regeneration. Nature.473: 326-335.

Makino, S., Fukuda, K., Miyoshi, S., Konishi, F., Kodama, H., Pan, J., Sano, M., Takahashi, T., Hori, S., Abe, H. and Hata, J.I. (1999). Cardiomyocytes can be generated from marrow stromal cells in vitro. J Clin Inves. 103(5): 697-705.

Malliaras, K., Zhang, Y., Seinfeld, J., Galang, G., Tseliou, E., Cheng, K., Sun, B., Aminzadeh, M. and Marbán, E. (2013). Cardiomyocyte proliferation and progenitor cell recruitment underlie therapeutic regeneration after myocardial infarction in the adult mouse heart. EMBO Mol. Med. 5(2): 191-209.

Mauritz, C., Schwanke, K., Reppel, M., Neef, S., Katsirntaki, K., Maier, L.S., Nguemo, F., Menke, S., Haustein, M., Hescheler, J. and Hasenfuss, G. (2008). Generation of functional murine cardiac myocytes from induced pluripotent stem cells. Circulation. 118(5): 507.

Medvedev, S.P., Shevchenko, A.I. and Zakian, S.M. (2010). Induced pluripotent stem cells: problems and advantages when applying them in regenerative medicine. Acta Naturae. 2(2): 18-28.

Mirnezami, R., Nicholson, J. and Darzi, A. (2012). Preparing for precision medicine. N Engl. J Med. 366(6): 489491.

Mohandas, T., Sparkes, R.S. and Shapiro, L.J. (1981). Reactivation of an inactive human $\mathrm{X}$ chromosome: evidence for $\mathrm{X}$ inactivation by DNA methylation. Science. 211(4480): 393-396.

Mollova, M., Bersell, K., Walsh, S., Savla, J., Das, L. T., Park, S.-Y., Silberstein, L. E., dos Remedios, C. G., Graham, D., Colan, S. (2013). Cardiomyocyte proliferation contributes to heart growth in young humans. Proc. Natl. Acad. Sci. 110: 1446-1451

Oh H., Bradfute S.B., Gallardo T.D., Nakamura T., Gaussin V., Mishina Y., Pocius J., Michael L.H., Behringer R.R., Garry D.J. Cardiac progenitor cells from adult myocardium: homing, differentiation, and fusion after infarction. Proc. Natl. Acad. Sci. USA. 2003; 100: 12313-12318.

Oh, H., Bradfute, S.B., Gallardo, T.D., Nakamura, T., Gaussin, V., Mishina, Y., Pocius, J., Michael, L.H., Behringer, R.R., Garry, D.J. and Entman, M.L. (2003). Cardiac progenitor cells from adult myocardium: homing, differentiation, and fusion after infarction. Proc. Natl. Acad. Sci. 100(21): 12313-12318.

Rangappa, S., Fen, C., Lee, E.H., Bongso, A. and Wei, E.S.K. (2003). Transformation of adult mesenchymal stem cells isolated from the fatty tissue into cardiomyocytes. Ann Thorac Surg. 
75(3): 775-779.

Senyo, S.E., Steinhauser, M.L., Pizzimenti, C.L., Yang, V.K., Cai, L., Wang, M., $\mathrm{Wu}$, T.D., Guerquin-Kern, J.L., Lechene, C.P. and Lee, R.T. (2013). Mammalian heart renewal by preexisting cardiomyocytes. Nature. 493(7432): 433-436.

Walsh, S., Pontén, A., Fleischmann, B. K. and Jovinge, S. (2010). Cardiomyocyte cell cycle control and growth estimation in vivo--an analysis based on cardiomyocyte nuclei. Cardiovasc. Res. 86, 365-373.

Yanagimachi, M.D., Niwa, A., Tanaka, T., Honda-Ozaki, F., Nishimoto, S., Murata, Y., Yasumi, T., Ito, J., Tomida, S., Oshima, K. (2013). Robust and highly-efficient differentiation of functional monocytic cells from human pluripotent stem cells under serum- and feeder cell-free conditions. PLoS One. 8(4): e59243.

Yoon, B.S., Yoo, S.J., Lee, J.E., You, S., Lee, H.T. and Yoon, H.S. (2006). Enhanced differentiation of human embryonic stem cells into cardiomyocytes by combining hanging drop culture and 5azacytidine treatment. Differentiation. 74(4): 149-159.

Yu, J., Vodyanik, M.A., Smuga-Otto, K., Antosiewicz-Bourget, J., Frane, J.L., Tian, S., Nie, J., Jonsdottir, G.A., Ruotti, V., Stewart, R. and Slukvin, I.I. (2007). Induced pluripotent stem cell lines derived from human somatic cells. Science. 318(5858): 1917-1920.

\section{How to cite this article:}

Purnima Singh, Tanmay Mondal, N. Mahalakshmi, Kuldeep Kumar, A.P. Madhusoodan, Mihir Sarkar and Sadhan Bag. 2019. Expression of GATA4 Gene into Differentiated Canine Induced Pluripotent Stem Cell. Int.J.Curr.Microbiol.App.Sci. 8(08): 457-464. doi: https://doi.org/10.20546/ijcmas.2019.808.052 